3 Research Square

\title{
Effect of domestication on phenotypic plasticity in chaya (Cnidoscolus aconitifolius (Mill) I.M. Johnstone)
}

Miguel A. Munguía-Rosas ( $\square$ munguiarma@cinvestav.mx )

Centro de Investigación y de Estudios Avanzados del Instituto Politécnico Nacional https://orcid.org/0000-0003-2319-1666

\section{Research Article}

Keywords: Chaya, Cnidoscolus aconitifolius, domestication, light environment, phenotypic plasticity, reaction norms

Posted Date: March 1st, 2021

DOI: https://doi.org/10.21203/rs.3.rs-276648/v1

License: (a) (i) This work is licensed under a Creative Commons Attribution 4.0 International License. Read Full License

Version of Record: A version of this preprint was published at Botanical Sciences on October 5th, 2021. See the published version at https://doi.org/10.17129/botsci.2879. 


\section{Abstract}

It is widely recognized that phenotypic plasticity may increase the survival of plants in environmentally variable habitats. However, the manner in which artificial selection affects the phenotypic plasticity of crops is poorly understood and there is no previous study in clonally propagated crops. The goal of this study was to assess the effect of domestication on phenotypic plasticity in leaf traits, growth rates and allocation patterns, under contrasting light environments, in the clonally propagated crop chaya (Cnidoscolus aconitifolious (Mill) I.M. Johnstone). Leaf area, leaf perimeter, leaf specific area, leaf production, trichome density, growth in height, growth in stem diameter and slenderness were measured in 97 clones belonging to 20 genotypes (10 wild and 10 domesticated). The clones were allocated to two contrasting light environments: fully exposed to sun $v s$. placement beneath a shade cloth. Reaction norms for each trait were compared between wild and domesticated clones. Results suggest that domestication and light environment had a non-additive effect on phenotypic plasticity in leaf production and slenderness. Reduced plasticity in these traits was observed in domesticated plants compared to that of their wild relatives. Leaf production and slenderness are associated with the shade avoidance syndrome, which is evident in wild plants but not manifested in domesticated plants. Reduced plasticity in leaf production also suggests yield stability, since the leaves form the edible part of chaya. I conclude that artificial selection reduces phenotypic plasticity in the yield of chaya and in its response to variation in the light environment.

\section{Introduction}

Temporal and spatial environmental heterogeneity is common in terrestrial ecosystems and sessile organisms such as plants must cope with this heterogeneity (Bazzas 1996; Valladares et al. 2007). Phenotypic plasticity (PP), broadly defined as the ability of a single genotype to express multiple phenotypes in response to environment changes (Bradshaw 1965; Schlichting and Pigliucci 1998; Sultan 2000), is recognized as one important way in which plants can deal with environmental heterogeneity (Bradshaw 1965; Bradshaw and Hardwick 1989). At present, it is widely accepted that PP is genetically inherited and therefore subject to selection and possibly adaptive (Via et al. 1995). Although PP has become a central topic in the ecology and evolution of wild plants (Valladares et al. 2007), the theme is still incipient in cultivated plants (Piperno et al. 2015; Matesanz and Milla, 2018). However, PP is important in these latter plants because the ability of crops to adjust to the environment may act to buffer the negative effects of climate change on crop yields (Nicotra et al. 2010; Desmarais et al. 2013).

Domestication is a human-driven selection process that has produced major changes in the phenotypes of cultivated plants (Meyer et al. 2012; Turcote et al. 2014), in which strong and consistent artificial selection may act to increase phenotypic uniformity (Meyer and Purugganan 2013). Reduced PP in yield (also known as yield stability) is often considered a desirable feature in cultivated plants (Peltonen-Sainio et al. 2011; Des Marais et al. 2013); however, yield instability can be also advantageous since it increases the capacity of these plants to exploit favorable environmental conditions and thus produce higher yields (Simmonds 1981; Sadras et al. 2009). Although PP in yields has received more attention due to the 
economic interest, other morphological and physiological traits can be also plastic and may underlie yield stability (Nicotra et al. 2010; Nicotra and Davidson 2010).

Experimental studies comparing reaction norms (i.e. array of phenotypes generated by an specific genotype in response to different environments; Schmalhausen 1949) of domesticated plants vs. their wild relatives (Matesanz and Milla 2018) are of particular importance to our understanding of how artificial selection (i.e. domestication) has affected PP. Under this approach, Matesanz and Milla (2018) recently found that domesticated and wild accessions showed non-parallel reaction norms in a set of morphological and physiological traits in response to variation in water availability in seven crops (chard [Beta vulgaris L.], cabbage [Brassica oleracea DC.], sunflower [Helianthus annuus L.], tomato [Solanum lycopersicum L.], durum wheat [Triticum durum Desf.], maize [Zea mays L] and pea [Pisum sativum L.]). According to that study, PP tends to be greater in domesticated plants, which are able to capitalize on greater water availability and outperform their wild relatives in terms of growth rates and biomass gain, while their performance does not differ when water availability is low. Similar results were seen in lettuce, where greater PP in root development was found in domesticated (Lactuca sativa L.) compared to wild (L. serriola L.) plants, under contrasting water availability (Gallardo et al. 1996). However, the opposite effect has been observed in maize (Doebley and Hubbard 1997; Doebley and Stec 1991) and millet (Setaria italica (L.) P Beauv \& S. viridis (L.) P Beauv; Doust and Kellogg 2006), in which the number of branches remained unaltered by plant density and/or light availability in domesticated plants, in contrast to the high PP exhibited by their wild relatives. Paradoxically, the same seven crops studied by Matesanz and Milla (2018) exhibited mainly parallel reaction norms for most traits under different nutrient levels. Therefore, the effect of domestication on PP may be contingent upon the particular environmental variable and species in question. Another aspect that may preclude a generalization is that all previous studies on the topic have utilized sexually reproduced crops as the study species.

Although vegetatively propagated plants such as banana (Mussa spp.), manioc (Manihot esculenta Crantz), potato (Solanum tuberosum L.) and sugarcane (Saccharum officinarum L.) are among the world's most important commercial crops, the evolution of these cultivars under domestication has received little attention (McKey et al. 2010; Denham et al. 2020). This is partly due to the debatable perception that the domestication of clonally propagated plants was "instantaneous" through clonal propagation of wild plants with desired phenotypes. However, under this perspective, it is difficult to envisage how vegetatively propagated plants could have accumulated the different, independently evolved, adaptations to agriculture they exhibit today (Meyer et al. 2012; Stetter et al. 2017). In a recent review, Duenham et al. (2020) suggested that the considerable phenotypic variation exhibited by vegetatively propagated cultivars is probably the result of plasticity rather than genotypic variation and thus the observed morphological differences between domesticated plants and their wild relatives may be due to environmental differences that prevail in their habitats. However, the evidence cited for this comes mainly from observational studies, some of which were not specifically designed to test for the effect of domestication on PP. For example, Ménard et al. (2013) observed that both wild and cultivated manioc exhibited different growth habits in different environments, but the authors did not control the genotype and therefore, PP sensu stricto remains to be confirmed. 
In this study, I assessed PP in traits related to yield, growth rate and resource allocation, as a response to light availability in chaya (Cnidoscolus aconitifolius (Mill) I.M. Johnstone), a clonally propagated crop with edible leaves (Ross-Ibarra and Molina-Cruz, 2002; Munguía-Rosas et al. 2019). Chaya offers an excellent study model with which to address the effect of domestication on PP since, in contrast to many other clonally propagated crops (Duenham et al. 2020), its domestication history, artificial selection targets and wild ancestor are all known (Ross-lbarra 2003; Munguía-Rosas et al. 2019; Solís-Montero et al. 2020). Chaya was domesticated by the Maya, who selected for plants with more, bigger and softer leaves (Munguia-Rosas et al. 2019). Domesticated and wild plants coexist; however, domesticated plants only grow in home gardens while the wild plants grow in a variety of habitats ranging from forest gaps to heavily disturbed vegetation (Munguía-Rosas et al. 2019). I selected light availability as the independent variable because chaya is a light demanding plant and the phenotypic response of these plants to shade is well known (i.e. the shade avoidance syndrome), featuring allocation of resources to height at the expense of leaves, branches and stems (Franklin 2008). My specific goal was to assess the effect of domestication on PP in leaf traits, growth rates and allocation patterns to light variation by comparing reaction norms between wild and domesticated chaya. If domestication affects PP, I expect non-parallel reaction norms in the selected traits of wild and domesticated plants.

\section{Materials And Methods}

\section{Study system}

Chaya (Cnidoscolus aconitifolius, (Mill) I.M. Johnstone, Euphorbiaceae) is a shrub of up to $5 \mathrm{~m}$ in height, distributed mainly in tropical America (Ross-lbarra and Molina-Cruz 2002). Chaya is a monoecious plant species (i.e. male and female flowers are produced by the same plant), and its short-lived ( $24 \mathrm{~h}$ ) flowers are insect-pollinated (Arceo-Gómez et al. 2009). The fruits are dry capsules containing up to three seeds that are dispersed ballistically (Standley and Steyermark 1949). The reproductive season lasts from March to November with a flowering peak in summer (Munguía-Rosas and Jácome-Flores 2020). The leaves are deciduous and have highly urticant trichomes, which are also present on the stems and fruit (Parra-Tabla et al. 2004; Abdala-Roberts and Parra-Tabla 2005). Trichome density and resource allocation is influenced by some environmental variables such as herbivory (Abdala-Roberts and Parra-Tabla 2005; Arceo-Gómez et al. 2009). Chaya grows in forest gaps and heavily anthropized habitats (Parra-Tabla et al. 2004).

Chaya was domesticated relatively recently by the Maya in the Yucatan Peninsula, where it is grown in home gardens and co-occurs with its wild relatives up to the present (Ross-lbarra 2003; Munguía-Rosas et al. 2019). Despite their co-occurrence, there is complete reproductive isolation between the wild and domesticated forms, mainly due to poor pollen production and fertility of the latter (Munguía-Rosas and Jácome-Flores 2020). The syndrome of domestication includes greater production of bigger leaves with significantly fewer trichomes (Munguía-Rosas et al. 2019; Solis-Montero et al. 2020). Domesticated plants are clonally propagated by stem cuttings, which are more succulent than those of their wild relatives (Munguía-Rosas et al. 2019). 


\section{Experimental design and data collection}

As a part of a bigger project, in summer 2017, stem cuttings from secondary branches were collected from 160 accessions in 40 different sites distributed across the Yucatan Peninsula, at a distance of at least $5 \mathrm{~km}$ apart (See Munguía-Rosas et al. 2019 for details). In each locality, one to four stem cuttings of cultivated (69) and wild (91) plants were collected and planted in an experimental plot located in the municipality of Merida in central Yucatan ( $21^{\circ} 01^{\prime} 18^{\prime \prime} \mathrm{N} ; 89^{\circ} 39^{\prime \prime}$ W; $11 \mathrm{~m}$ a.s.l.). Several cuttings, particularly those of the wild plants, failed to develop roots or died a few weeks later. By April 2019, the plantation had 67 adult plants (33 wild and 34 domesticated), all of which were sexually mature (produced flowers). Although the wild plants produce seeds, I propagated the plants from stem cuttings for standardization due to the low fertility of domesticated plants.

Since plants in the field were variable in size and some have only a small number of secondary branches, or none at all (i.e. only the main stem is present), I used the plantation described above as a source of cuttings for the plasticity experiment (see below). The fact that all of the plants in the plantation were of the same age and had grown under the same environmental conditions reduced the potential for mother effects. In June 2019, I selected and cut 8 stems from secondary branches of 20 different (10 wild and 10 cultivated) mother plants ( $n=160$ cuttings; hereafter referred as genotypes). The selection criteria of the mother plants were that they: (i) had at least 10 secondary branches, (ii) were apparently heathy (i.e. showed no sign of pathogens and/or herbivory) and (iii) were similar in height (1.5-2 $\mathrm{m}$ ). The selected stems were $30 \mathrm{~cm}$ in length and $1-1.5 \mathrm{~cm}$ in width and were cut diagonally at $1-2 \mathrm{~cm}$ from the nearest node. Stem cuttings were planted in $6 \mathrm{~L}$ pots with a 7:3 mix of local soil and gravel, placed in a plant nursery with full exposure to sunlight and watered as required. Within the first month after planting, stems with signs of wilting or rotting were replaced. Despite this replacement procedure, one year later, only 97 plants ( 64 domesticated and 33 wild) from the 20 genotypes had survived. The difference in sample size was due to greater mortality rate in wild plants. Approximately half of the clones available per genotype were allocated randomly to one of two different light environments: full exposure to sunlight $(n=48$ plants; 14 wild, 34 domesticated) or grown beneath a nylon shade cloth ( $\mathrm{n}=49$ plants; 19 wild and 30 domesticated). Genotypes with a single clone (one genotype for domesticated and two genotypes for wild plants) were also randomly allocated to a light environment. I measured the photosynthetic active radiation (PAR) at six different points beneath the cloth (hereafter referred to as the "shaded" environment) and near clones fully exposed to sunlight (hereafter, the "open" environment) at $1200 \mathrm{~h}$ on a clear, sunny day with a LI-500 light sensor logger (LI-COR, Lincoln, NE, USA). The PAR available in the shaded environment $\left(156 \pm 53 \mu \mathrm{mol} \cdot \mathrm{m}^{2} \cdot \mathrm{s}^{-1}\right)$ was only $22 \%$ of that recorded in the open spaces $(696 \pm 36$ $\mu \mathrm{mol} \cdot \mathrm{m}^{2} \cdot \mathrm{s}^{-1}$ ).

Data collection began one month (July 2020) after allocating the clones to their respective light treatments in July 2020. At that time, all of the plants were aged 12-13 months. Once a month, and for a period of six months, plant height and the diameter at the base of the main stem were measured. Every month, the number of leaves was counted and one fully expanded leaf, with no visible damage, was collected from each plant. These leaves were then taken to the laboratory where the area and perimeter 
were measured with a leaf area meter (CID Biosciences Inc. Cl-202, Camas, WA, USA). The number of trichomes on the leaf border were also counted because, on this part of the leaf, there is a larger density of trichomes and also because the trichomes on other parts of the leaves were scarce or absent in the domesticated plants and, therefore, not comparable (Solís-Montero et al. 2020). Leaves collected during the last month of sampling were also weighed fresh and after being oven-dried at $75^{\circ} \mathrm{C}$ for $36 \mathrm{~h}$.

\section{Data processing and statistical analyses}

Since the longevity of fully expanded leaves is shorter than the duration of the inter-sampling periods, I used the monthly leaf count as a proxy of leaf production per plant during the experiment. Leaf trichomes were expressed as number of trichomes per $\mathrm{cm}$ in length to control for leaf size. I also calculated the absolute growth rate in height and in stem diameter as: $x_{2}-x_{1} \cdot\left(t_{2}-t_{1}\right)^{-1}$ where $x_{1}$ and $x_{2}$ are plant height or stem diameter during the first $\left(t_{1}\right)$ and last $\left(t_{2}\right)$ weeks of sampling. Furthermore, I calculated a slenderness index as the plant height divided by the diameter of the stem at the end of the experiment (Barros et al. 2011). I calculated the leaf specific area (LSA) of leaves collected during the last week of sampling by dividing the leaf area by its dry mass.

I used generalized linear mixed models to assess the main effect of domestication (two levels: wild vs. domesticated), light environment (open $v s$. shaded) and their interaction, on eight phenotypic traits: (i) leaf size (leaf area in $\mathrm{cm}^{2}$ ), (ii) leaf perimeter in $\mathrm{cm}$, (iii) $\mathrm{LSA}$ in $\mathrm{cm}^{2} \cdot \mathrm{g}^{-1}$, (iv) leaf production in number of leaves produced in six months, (v) number of trichomes $\mathrm{cm}^{-1}$, (vi) growth in height $\left(\mathrm{mm} \cdot \mathrm{week}^{-1}\right)$, (vii) growth in stem diameter $\left(\mathrm{mm} \cdot\right.$ week $\left.^{-1}\right)$ and (viii) the slenderness index $\left(\mathrm{mm} \cdot \mathrm{cm}^{-1}\right)$. Leaf variables i, ii, iv and $v$ are known selection targets in chaya, with variable iv also representing the yield (Munguía-Rosas et al. 2019), while variables iii and vi-viii are related to changes exhibited by plants under limited light conditions (Griffith and Sultan 2005; Barros et al. 2011). A Gaussian error distribution was assumed for all of these variables, except leaf production, for which a Poisson error distribution was chosen. In all models, genotype was included as a random grouping factor. Additionally, in the case of leaf size, leaf perimeter and trichomes, leaves nested in plant were also included in the random part of the models to account for repeated measures. Owing to variation in the structure of the random part of the model, as well the incidence of missing data (i.e. some leaves did not met selection criteria), the denominator degrees of freedom varied among models. I inferred differential phenotypic plasticity between wild and domesticated plants when the interaction domestication $x$ light environment was significant. In that case, one-way analyses within a single level of the second factor were then performed in order to elucidate the nature of the interaction.

The direction and intensity of reaction norms among wild and domesticated plants was expressed as the slope between mean values and between light environments for each domestication level and phenotypic trait (Morrisey and Liefting 2016). Although the slope of the reaction norms is suitable to show the phenotypic change produced by the environment, it offers little opportunity for comparing PP among different traits, given the differences in units. I therefore also calculated a plasticity index based on relative distance (RDPI), as outlined by Valladares et al. (2006), which is easy to interpret and compare 
(range: 0 [no plasticity] - 1 [maximal plasticity]). The RDPI is defined as the difference between minimum and maximum trait values divided by the maximum trait value. The index was calculated per genotype, when more than one clone survived per genotype and per environment, using the mean values of phenotypic traits (Valladares et al. 2006). I show only one value per trait, which is the sum of phenotypic distances for each genotype divided by the number of genotypes (Valladares et al. 2006). Genotypes with only one clone were not used to calculate RDPI. To assess inter-genotype variation, I calculated the coefficient of variation (CV) of RDPI at genotype level for each trait for wild and domesticated plants.

All of the analyses were run in R 4.0.3 (R Core Team 2020). All data are available as online supplementary material.

\section{Results}

\section{Environmental and domestication effects.}

All traits were significantly affected by the light environment, apart from growth in stem diameter (Table 1). Similarly, most of the traits measured (leaf area, leaf perimeter, trichome density and growth in height and stem diameter) were affected by domestication (Table 1). Interaction between light environment and domestication was significant for leaf production and the slenderness index (Table 1). However, the effect of these factors was additive for the rest of the traits measured (Table 1, Fig, 1). On examination of the significant interactions, I found that, while domesticated plants did not produce a significantly different number of leaves in the two light environments $\left(\chi^{2}{ }_{1}=2.76, P=0.09\right)$, the wild plants $\left(\chi^{2}{ }_{1}=\right.$ 16.36, $P<<0.01$ ) produced significantly less leaves in the shaded than in the open environment (Fig. 1D). Wild plants also exhibited a significantly higher slenderness index than domesticated plants in the shaded environment $\left(F_{1,43}=3.33, P=0.04\right)$; however, wild and domesticated plants did not differ in this regard in the open environment $\left(F_{1,43}=0.28, P=0.60\right)($ Fig. $1 \mathrm{H})$.

Plants in the open environment produced 1.08 times more leaves and with 1.11 times more trichomes than those in the shaded environment. However, the leaves of the plants in the open were 1.25 times smaller and presented perimeter and LSA values that were 1.09 and 1.48 times lower, respectively, than those of the plants in the shaded environment (Table 2). Regarding plant growth, plants in the shaded environment presented faster growth in height and greater slenderness than plants in the open (Table2). Regardless of the light environment, the domesticated plants produced leaves with 1.39 times greater leaf area and presented a more rapid growth in height (1.18 times) and in stem diameter ( 3.85 times) than the wild plants. However, the domesticated plants also produced leaves with 1.13 times smaller perimeter and 1.49 times fewer trichomes than the wild plants (Table 2).

\section{Intensity and variation of phenotypic plasticity}

The reaction norms of wild plants exhibited steeper slopes than domesticated plants in most of the traits measured, although to a variable extent (Table 3). Specifically, leaf production was 7.38 times, slenderness 2.59 times, growth in height 2.31 times, trichome density 1.47 times, LSA 1.15 times and 
growth in stem diameter 1.14 times greater in wild than in domesticated plants (Table 3 ). In contrast, the domesticated plants presented reaction norms with steeper slopes only for leaf perimeter (4.86 times) and leaf area (1.74 times) (Table 3). In general, the slopes of the reaction norms of wild and domesticated plants had the same sign, except for growth in stem diameter, which was positive in domesticated but negative in wild plants (Table 3, Fig. 1). The RDPI for phenotypic traits in wild genotypes ranged from 0.11 (trichome density) to 0.64 (growth in stem diameter) and averaged $0.29 \pm$ 0.05. The same index for domesticated plants ranged from 0.09 (growth in height) to 0.71 (growth in stem diameter) and averaged $0.24 \pm 0.07$ (Table 3). In general, the RDPI was greater in wild than in domesticated plants for most traits (63\%) and, when the opposite was found, the differences were relatively low $(\Delta=0.04-0.07)$ (Table 3).

The coefficient of variation for RDPI at genotype level ranged from 50.33 to $87.12 \%$ (mean: $65.78 \pm$ $1.71 \%$ ) for wild genotypes and from 42.49 to $120.01 \%$ (mean: $69.62 \pm 3.04 \%$ ) for domesticated genotypes (Table 3). Differences in the $\mathrm{CV}$ between wild and domesticated genotypes tended to be low (mean $\Delta=14.00 \pm 3.00 \%$ ), except for leaf production ( $\Delta=65 \%$ ), which was evidently greater than the mean (Table 3). In all traits measured, one or two genotypes showed the opposite pattern relative to the rest (Fig. 2).

\section{Discussion}

In this study, I have shown that domestication and the light environment have a non-additive effect on phenotypic plasticity in leaf production and slenderness in chaya. Reduced plasticity in these traits was observed in domesticated plants compared to their wild relatives. Wild plants exhibited greater PP than domesticated plants in other traits (leaf perimeter, LSA and growth in height), albeit to a lesser extent (non-intersecting reaction norms). Although wild and domesticated plants exhibited some degree of plasticity in response to the light environment in all measured traits, the morphological differences between wild and domesticated plants were mostly consistent in the two light environments. These results suggest that artificial selection has not only changed the phenotype of chaya, but has also reduced PP in some traits.

The non-additive effect of the domestication $\mathrm{x}$ light environment interaction on the number of leaves is compatible with the notion that artificial selection may lead to relative yield stabilization (Peltonen-Sainio et al. 2011; Des Marais et al. 2013). In contrast to the wild plants, which produced fewer leaves in the shaded than in the open environment, leaf production in domesticated plants did not exhibit significant variation between light environments. Leaves are the edible part of chaya and leaf production is one of traits that have been deliberately selected by the growers in the Yucatan (Munguía-Rosas et al. 2019). I therefore suggest that artificial selection has limited the PP in leaf production in domesticated chaya (i.e. yield stability). Similar results have been reported previously in some cultivated accessions of maize (Doebley and Stec 1991; Doebley et al. 1997) and millet (Doust and Kellogg 2006), in which limited plasticity to light/density were observed in axillary branches relative to that of the wild relatives. In contrast, Matesanz and Milla (2018) found greater PP in domesticated accessions than in wild relatives 
of chard, cabbage, sunflower, tomato, durum wheat, maize and pea. Moreover, Gallardo et al. (1996) found greater PP for root development in domesticated lettuce. Since the previous studies measured PP under environmental variables (water and nutrient availability) that were not evaluated in this research and, in contrast to this study, all of the previously studied crops were sexually reproduced, short-lived herbaceous plants, I am unable to infer the cause(s) of differences between those studies and the present study.

The domestication $x$ environment interaction was also significant for the slenderness index. While slenderness was undistinguishable between wild and domesticated plants in the open environment, wild plants exhibited greater slenderness than domesticated plants in the shaded environment. The plastic response of wild plants in terms of slenderness and leaf production is in accordance with the shade avoidance syndrome in which plants under light limitation reduce resource investment in leaf production and stem thickening, in order to reallocate them to growth in height (Griffith and Sultan 2005; Franklin 2008). Although this interaction was not significant for growth in height, the steeper slope and greater PP index observed in wild plants for this trait support the notion that the shade avoidance syndrome is more evident in wild than in domesticated chaya. Artificial selection could have constrained the ability of domesticated plants to reallocate resources when facing light limitation.

Although the reaction norms of wild and domesticated plants did not intersect in most traits (i.e. nonsignificant domestication $\mathrm{x}$ environment interaction), those of the wild plants presented steeper slopes and/or greater PP indexes than the cultivated plants in most of these traits (see Fig. 1 and Table 3); i.e. despite the plasticity exhibited, wild and cultivated chaya differed morphologically in the two light environments in terms of leaf area, trichome density and growth in height and stem diameter. This suggests that the morphological difference observed between wild and domesticated plants in their respective habitats (i.e. home gardens for domesticated plants and secondary forest/anthropized habitat for wild plants) is not due to PP, as has recently been suggested by Denham et al. (2020) for clonally propagated plants. Domesticated chaya did not regress to "the wild phenotype" when growing in a common garden resembling the habitat of wild chaya (Munguía-Rosas et al. 2019); indeed, contrary to previous suggestions (McKey et al. 2010; Denham et al. 2020), it exhibited a set of traits compatible with a domestication syndrome i.e. domesticated chaya had more, bigger, and softer leaves as well as more succulent stems (Munguía-Rosas et al. 2019). As is the case in sexually reproduced crops, these traits are related to the size and palatability of the edible part, as well as ease of cultivation (McKey et al. 2010; Meyer et al. 2012). As with other crops, wild and domesticated chaya probably simultaneously exhibit phenotypic differences and important PP despite artificial selection, since the trait mean and variance (i.e. PP) are genetically decoupled (Des Marais et al. 2013).

Regarding the magnitude of plasticity, the RDPI averaged $0.29 \pm 0.05$ (range: $0.11-0.64$ ) in wild and 0.24 \pm 0.07 (range: $0.12-0.71$ ) in domesticated chaya for pooled traits. The direction (wild > domesticated) and magnitude (1.3-fold) of this difference concurs with the review of Des Marais et al. (2013), who reported greater (1.8-fold) plasticity in natural than in cultivated crop species, a difference that the authors attributed to historical artificial selection for environmentally stable crops. However, these results 
must be interpreted with caution because these authors reviewed studies that adopted a wide variety of approaches and phylogenetically unrelated species (See supplementary materials in Des Marais et al. 2013). To make a sensible comparison with previous studies using a similar approach, I calculated the RDPI using mean phenotypic values in the different environments provided by the authors. This exercise was restricted to the traits that I also measured in this study. For the seven crops studied by Matesanz and Milla (2018), the RDPI for leaf area had an average value of 0.24 for wild and 0.26 for domesticated plants in environments under contrasting nutrient availability. These values are very similar to those reported here for chaya (wild $=0.21$, domesticated $=0.24$ ). However, the RDPI values for the same trait, but under contrasting water environments (wild $=0.28$, domesticated $=0.45$ ), were substantially higher than that observed in chaya, particularly for domesticated plants. The RDPI for growth in height was also similar between the wild plants (wild chaya $=0.21$, wild relatives of previously studied crops $=0.21-0.29$ ) but substantially different between domesticated plants (chaya $=0.09$, other crops $=0.44-0.56$ ). Again, because there are several differences between the crops studied by Matesanz and Milla (2018) and chaya, I could not identify the factor underlying the differences between studies. Not only did this and previous studies manipulate different environmental variables, but also the plants present several differences in life history traits and cultivation modes. Regarding the latter, to my knowledge, no previous experiment has compared reaction norms between wild and domesticated plants in a clonally propagated crop.

Variation in PP among genotypes was important for wild (CV range: $50-87 \%$ ) as well as domesticated (CV range: $42.49-120 \%$ ) plants. This variation was highly influenced by $1-2$ genotypes of wild and domesticated plants that exhibited either the opposite trend compared to the rest or an exacerbated plasticity in the same direction as that of the rest of genotypes (Fig. 2). The presence of genotypes with atypical reaction norms may be due to spatial variation in the strength, duration and/or direction of artificial selection. The genotypes used in this study came from different populations across all over the Yucatan peninsula (see the Materials and Methods section). Growers may therefore have selected different traits in some populations. Indeed, a previous study identified four different varieties of domesticated chaya based on leaf shape in Mexico and Guatemala (Ross-lbarra 2003), supporting the notion that growers have selected different traits across the distribution rage of chaya. Other authors have suggested that chaya was recently domesticated and artificial selection has simply had insufficient time to filter undesired phenotypes (Munguía-Rosas et al. 2019).

In conclusion, domestication in chaya affects PP in response to the light environment. Changes in PP are particularly relevant to leaf production and slenderness. Domesticated chaya also exhibits an attenuated shade avoidance syndrome compared to that of its wild progenitors. Despite this plasticity, differences between wild and domesticated plants are consistent throughout contrasting light environments in most of the traits measured. Further research in other crops is required to assess the generality of these results. Since PP can be measured in different ways, and the combination of phenotypic traits measured and environmental variables manipulated could be overwhelming, future studies could consider standardizing these aspects in order to more efficiently advance our understanding of phenotypic plasticity in plants under domestication. 


\section{Declarations}

Acknowledgments: GJ Villicaña-Hernández, MV Solís-Montero and E Ochoa-Estrada kindly helped with the preparation of the plasticity experiment. My son, lan B Munguía-Torales, helped with leaf trait measurements during confinement due to the covid-19 pandemic.

Funding: This research was funded by a SEP-Cinvestav project (Reference Number: IDSC2018/22).

Conflicts of interest: The author does not have any conflict of interest.

Availability of data: Raw data is available as supplementary material.

Authors' contributions: MAM-R designed the study, collected and analysed data and wrote the manuscript.

\section{References}

Abdala-Roberts L, Parra-Tabla V (2005) Artificial defoliation induces trichome production in the tropical shrub Cnidoscolus aconitifolius (Euphorbiaceae). Biotropica 37: 251-257.

Arceo-Gómez G, Parra-Tabla V, Navarro J (2009) Changes in sexual expression as result of defoliation and environment in a monoecious shrub in Mexico: Implications for Pollination. Biotropica 41: 435 - 441.

Barros FV, Goulart MF, Sá Telles SB, Lovato MB, Valladares F, de Lemus-Filho JP (2011) Phenotypic plasticity to light of two congeneric trees from contrasting habitats: Brazilian Atlantic Forest versus cerrado (savanna). Plant Biol 14: 208-215.

Bazzaz FA (1996) Plants in changing environments: Linking physiological, population, and community ecology. Cambridge University Press, Cambridge.

Bradshaw AD (1965) Evolutionary significance of phenotypic plasticity in plants. Adv Genet 13:115-55.

Bradshaw AD, Hardwick K (1989) Evolution and stress - genotypic and

phenotypic components. Biol J Linn Soc 37: 137-155.

Denham T, Barton H, Castillo C, Crowther A, Dotte-Sarout E, Florin SA, Pritchard J, Barron A, Zhang Y, Fuller DQ (2020) The domestication syndrome in vegetatively propagated field crops. Ann Bot-London 125: 581-597.

Des Marais DL, Hernandez KM, Juenger TE (2013) Genotype-by-environment interaction and plasticity: Exploring genomic responses of plants to the abiotic environment. Annu Rev Ecol Syst 44: 5-29. 
Doebley J, Stec A, Hubbard L (1997) The evolution of apical dominance in maize.

Nature 386: 485-488.

Doebley J, Stec A (1991) Genetic analysis of the morphological differences between

maize and teosinte. Genetics 129: 285-295.

Doust AN, Kellogg EA (2006) Effect of genotype and environment on branching in weedy

green millet (Setaria viridis) and domesticated foxtail millet (Setaria italica) (Poaceae). Mol Ecol 15:

1335-1349.

Franklin KA (2008) Shade avoidance. New Phytol 179: 930-944.

Griffith TM, Sultan SE (2005) Shade tolerance plasticity in response to neutral vs green shade cues in $\mathrm{k}$ species of contrasting ecological breadth. New Phytol 166: 141-148.

Matesanz S, Milla R (2018) Differential plasticity to water and nutrients between

crops and their wild progenitors. Environ Exp Bot 145: 54-63.

McKey D, Elias M, Pujol B, Duputié A (2010) The evolutionary ecology of clonally propagated domesticated plants. New Phytol 186: 318-332.

Ménard L, McKey D, Muhlen GS, Vlair B, Rowe NP (2013) The evolutionary fate of phenotypic plasticity and functional traits under domestication in manioc: changes in stem biomechanics and the appearance of stem brittleness. PLoS One 8: e74727.

Meyer RS, DuVal AE, Jensen HR (2012) Patterns and processes in crop domestication: an historical review and quantitative analysis of 203 global food crops. New Phytol 196: 29 - 48.

Meyer RS, Purugganan MD (2013) Evolution of crop species: genetics of domestication and diversification. Nature Rev Genet 14: 840 - 852.

Morrissey MB, Liefting M (2016) Variation in reaction norms: Statistical considerations and biological interpretation. Evolution 70: $1944-1959$.

Munguía-Rosas MA, Jácome-Flores ME, Bello-Bedoy R. Solís-Montero V, Ochoa-Estrada, E (2019) Morphological divergence between wild and cultivated chaya (Cnidoscolus aconitifolius (Mill.) I.M. Johnst). Genet Resour Crop Ev 66: 1389-1398.

Munguía-Rosas MA, Jácome-Flores ME (2020) Reproductive isolation between wild and domesticated chaya (Cnidoscolus aconitifolius) in sympatry. Plant Biol 22: 932-938.

Nicotra AB, Davidson A (2010) Adaptive plasticity in water use traits. Funct Plant Biol 37: 117-127. 
Nicotra AB, Atkin OK, Bonser SP, Davidson AM, Finnegan EJ, Mathesius U, Poot P, Purugganan MD, Richards CL, Valladares F, va Kleunen M (2010) Plant phenotypic plasticity in a changing climate. Trends Plant Sci 15: 684-692.

Parra-Tabla V, Rico-Gray V, Carbajal M (2004) Effect of defoliation on leaf growth, sexual expression and reproductive success of Cnidoscolus aconitifolius (Euphorbiaceae). Plant Ecol 173: 153-160.

Peltonen-Sainio P, Jauhiainen L, Sadras VO (2011) Phenotypic plasticity of yield and agronomic traits in cereals and rapeseed at high latitudes. Field Crop Res 124: 261-269.

Piperno DR, Holst I, Winter K, McMillan O (2015) Teosinte before domestication: Experimental study of growth and phenotypic variability in Late Pleistocene and early Holocene environments. Quatern Int 363: 65-77.

R Core Team (2020) R: A language and environment for statistical computing. R Foundation for Statistical Computing, Vienna.

Ross-Ibarra J, Molina-Cruz A (2002) The ethnobotany of chaya (Cnidoscolus aconitifolius SSP. Aconitifolius Breckon): a nutritious Maya vegetable. Econ Bot 56: 350-365.

Ross-lbarra, J (2003) Origen y domesticación de la chaya (Cnidoscolus aconitifolius Mill I.M., M. Johnst): La espinaca Maya. Mexican Studies 19: 287-302.

Sadras VO, Reynolds M, De la Vega AJ, Petrie PR, Robinson R (2009) Phenotypic plasticity of phenology and yield in wheat, sunflower and grapevine. Field Crop

Res 110: 242-250.

Schlichting CD, Pigliucci M (1998) Phenotypic Evolution: A Reaction Norm perspective. Sinauer Associates, Sunderland.

Schmalhausen II (1949) Factors of evolution. Blakinston, Philadephia.

Simmonds NW (1981) Genotype (G), environment (E) and GE components of crop yield. Exp Agr 17:355362.

Standley PC, Steyermark JA (1949) Flora of Guatemala, Vol. 24, Part VI. Chicago Natural History Museum, Chicago.

Solís-Montero V, Martínez-Natarén DA, Parra-Tabla V, Ibarra-Cerdeña C, Munguía-Rosas MA (2020) Herbivory and anti-herbivore defences in wild and cultivated Cnidoscolus aconitifolius. disentangling domestication and environmental effects. AoB Plants 12: plaa023. 
Sultan SE (2000) Phenotypic plasticity for plant development, function and life history. Trends Plant Sci 5: 537-542.

Stetter MG, Gates DJ, Mei W, Ross-Ibarra J (2017) How to make a domesticate. Curr Biol 27: R896-R900.

Turcotte MM, Turley NE, Johnson (2014) The impact of domestication on resistance to two generalist herbivores across 29 independent domestication events. New Phytol 204: 671-681.

Valladares F, Sánchez-Gómez D, Zavala MA (2006) Quantitative estimation of phenotypic plasticity: bridging the gap between the evolutionary concept and its ecological applications. J Ecol 94: 1103-1116.

Valladares F, Gioali E, Gómez JM (2007) Ecological limits to plant phenotypic plasticity. New Phytol 176: 749-763.

Via S, Gomulkiewicz R, De Jong G, Scheiner SM, Schlichting CD, Van Tienderen PH (1995) Adaptive phenotypic plasticity: consensus and controversy. Trends Ecol Evol 10: 212-217.

\section{Tables}

Table 1. Effects of environment (open vs. shaded) and domestication (wild vs. domesticated) and their interaction on eight vegetative traits (Trait) in Cnidoscolus aconitifolius. Leaf area, leaf perimeter, leaf specific area (LSA), leaf production, trichome density (Trichomes) growth in height (Height) and stem diameter (Stem diameter), as well as a slenderness index (Slenderness). 


\begin{tabular}{|c|c|c|}
\hline Trait & Source of variation & Statistics \\
\hline \multirow[t]{3}{*}{ Leaf area } & Environment & $F_{1,66}=11.37^{\star \star}$ \\
\hline & Domestication & $F_{1,17}=25.71^{\star \star}$ \\
\hline & Environment x Domestication & $F_{1,66}=1.02$ n.s. \\
\hline \multirow[t]{3}{*}{ Leaf perimeter } & Environment & $F_{1,66}=4.65^{\star}$ \\
\hline & Domestication & $F_{1,17}=5.03^{\star}$ \\
\hline & Environment x Domestication & $F_{1,66}=1.14$ n.s. \\
\hline \multirow[t]{3}{*}{ LSA } & Environment & $F_{1,59}=15.19 * *$ \\
\hline & Domestication & $F_{1,17}=0.46$ n.s. \\
\hline & Environment x Domestication & $F_{1,59}=0.16$ n.s. \\
\hline \multirow[t]{3}{*}{ Leaf production } & Environment & $x^{2}=13.41 * *$ \\
\hline & Domestication & $x^{2}{ }_{1}=0.23$ n.s. \\
\hline & Environment x Domestication & $x^{2}=5.75^{\star}$ \\
\hline \multirow[t]{3}{*}{ Trichomes } & Environment & $F_{1,66}=15.24^{\star \star}$ \\
\hline & Domestication & $F_{1,17}=44.99 \star \star$ \\
\hline & Environment x Domestication & $F_{1,66}=0.14$ n.s. \\
\hline \multirow[t]{3}{*}{ Height } & Environment & $F_{1,68}=5.19 *$ \\
\hline & Domestication & $F_{1,68}=10.63^{\star \star}$ \\
\hline & Environment x Domestication & $F_{1,68}=0.35$ n.s. \\
\hline \multirow[t]{3}{*}{ Stem diameter } & Environment & $F_{1,68}=0.09$ n.s. \\
\hline & Domestication & $F_{1,68}=3.14$ * \\
\hline & Environment x Domestication & $F_{1,68}=0.37$ n.s. \\
\hline \multirow[t]{3}{*}{ Slenderness } & Environment & $F_{1,68}=19.71^{\star \star}$ \\
\hline & Domestication & $F_{1,68}=0.72$ n.s. \\
\hline & Environment x Domestication & $F_{1,68}=3.73^{\star}$ \\
\hline
\end{tabular}


n.s. $=$ No significant effect, $* P<0.05, \star \star P<0.01$.

Table 2. Mean values ( \pm 1 SE) of eight vegetative phenotypic traits (Trait) of wild and domesticated (Domestication) Cnidoscolus aconitifolius under two contrasting light environments (Environments): sun $v s$. shade. Traits measured were: Leaf area, leaf perimeter, leaf specific area (LSA), leaf production, trichome density (Trichomes) growth in height (Height) and in stem diameter (Stem diameter) as well as a slenderness index (Slenderness). Different superscript letters indicate statistically significant differences $(P<0.05)$ between factor levels: open $v s$. shade or wild $v s$. domesticated.

\begin{tabular}{|c|c|c|c|c|}
\hline & Environment & & Domestication & \\
\hline Trait & Open & Shaded & Wild & Domesticated \\
\hline $\begin{array}{l}\text { Leaf area } \\
\left(\mathrm{cm}^{2}\right)\end{array}$ & $55.81 \pm 1.36^{a}$ & $70.01 \pm 3.15^{b}$ & $48.95 \pm 1.79^{a}$ & $68.47 \pm 2.19^{b}$ \\
\hline $\begin{array}{l}\text { Leaf perimeter } \\
(\mathrm{cm})\end{array}$ & $44.24 \pm 0.91^{a}$ & $48.11 \pm 1.11^{\mathrm{b}}$ & $49.94 \pm 1.52^{\mathrm{a}}$ & $44.35 \pm 0.76^{b}$ \\
\hline $\begin{array}{l}\text { LSA } \\
\left(\mathrm{cm}^{2} \cdot \mathrm{g}^{-1}\right)\end{array}$ & $379.74 \pm 20.22^{\mathrm{a}}$ & $560.78 \pm 54.58^{b}$ & $420.74 \pm 67.89^{a}$ & $498.76 \pm 31.89^{a}$ \\
\hline $\begin{array}{l}\text { Leaf production } \\
\text { (n) }\end{array}$ & $41.02 \pm 2.62^{a}$ & $37.96 \pm 2.77^{b}$ & $39.12 \pm 2.91^{\mathrm{a}}$ & $39.62 \pm 2.48^{a}$ \\
\hline Trichomes (Trichomes $\cdot \mathrm{cm}^{-1}$ ) & $6.87 \pm 0.19^{a}$ & $6.22 \pm 0.18^{b}$ & $8.53 \pm 0.22^{\mathrm{a}}$ & $5.71 \pm 0.12^{b}$ \\
\hline $\begin{array}{l}\text { Height } \\
\left(\mathrm{mm} \cdot \text { week }^{-1}\right)\end{array}$ & $28.91 \pm 0.95^{a}$ & $31.69 \pm 1.02^{b}$ & $27.02 \pm 1.02^{\mathrm{a}}$ & $31.91 \pm 0.84^{b}$ \\
\hline $\begin{array}{l}\text { Stem diameter } \\
\left(\mathrm{mm} \cdot \text { week }^{-1}\right)\end{array}$ & $0.59 \pm 0.15^{\mathrm{a}}$ & $0.63 \pm 0.21^{a}$ & $0.21 \pm 0.55^{\mathrm{a}}$ & $0.81 \pm 0.18^{b}$ \\
\hline $\begin{array}{l}\text { Slenderness } \\
\left(\mathrm{cm} \cdot \mathrm{mm}^{-1}\right)\end{array}$ & $4.72 \pm 0.16^{a}$ & $5.75 \pm 0.21^{b}$ & $5.52 \pm 0.34^{a}$ & $5.11 \pm 0.14^{\mathrm{a}}$ \\
\hline
\end{tabular}

Table 3. Slope of reaction norms (Slope), phenotypic plasticity index (RPDI) and coefficient of variation of RPDI at genotype level (CV) for wild and domesticated plants of Cnidoscolus aconitifolious growing under two contrasting light environments. Traits measured were: Leaf area, leaf perimeter, leaf specific 
area (LSA), leaf production, trichome density (Trichomes) growth in height (Height) and in stem diameter (Stem diameter) as well as a slenderness index (Slenderness).

\begin{tabular}{|lllllll|}
\hline & Slope & & & RPDI & CV (\%) & \\
\hline Trait & Wild & Domesticated & Wild & Domesticated & Wild & Domesticated \\
\hline Leaf area & 9.48 & 16.49 & 0.21 & 0.24 & 51.42 & 58.51 \\
\hline Leaf perimeter & 1.01 & 4.91 & 0.23 & 0.12 & 77.63 & 71.19 \\
\hline LSA & 210 & 183 & 0.31 & 0.29 & 67.61 & 53.13 \\
\hline Leaf production & -7.31 & -0.99 & 0.31 & 0.21 & 54.94 & 120.01 \\
\hline Trichomes & -0.91 & -0.62 & 0.11 & 0.15 & 76.98 & 75.52 \\
\hline Height & 4.95 & 2.15 & 0.21 & 0.09 & 87.12 & 82.73 \\
\hline Stem diameter & -0.16 & 0.14 & 0.64 & 0.71 & 60.28 & 42.49 \\
\hline Slenderness & 1.79 & 0.69 & 0.31 & 0.15 & 50.33 & 53.43 \\
\hline
\end{tabular}

\section{Figures}



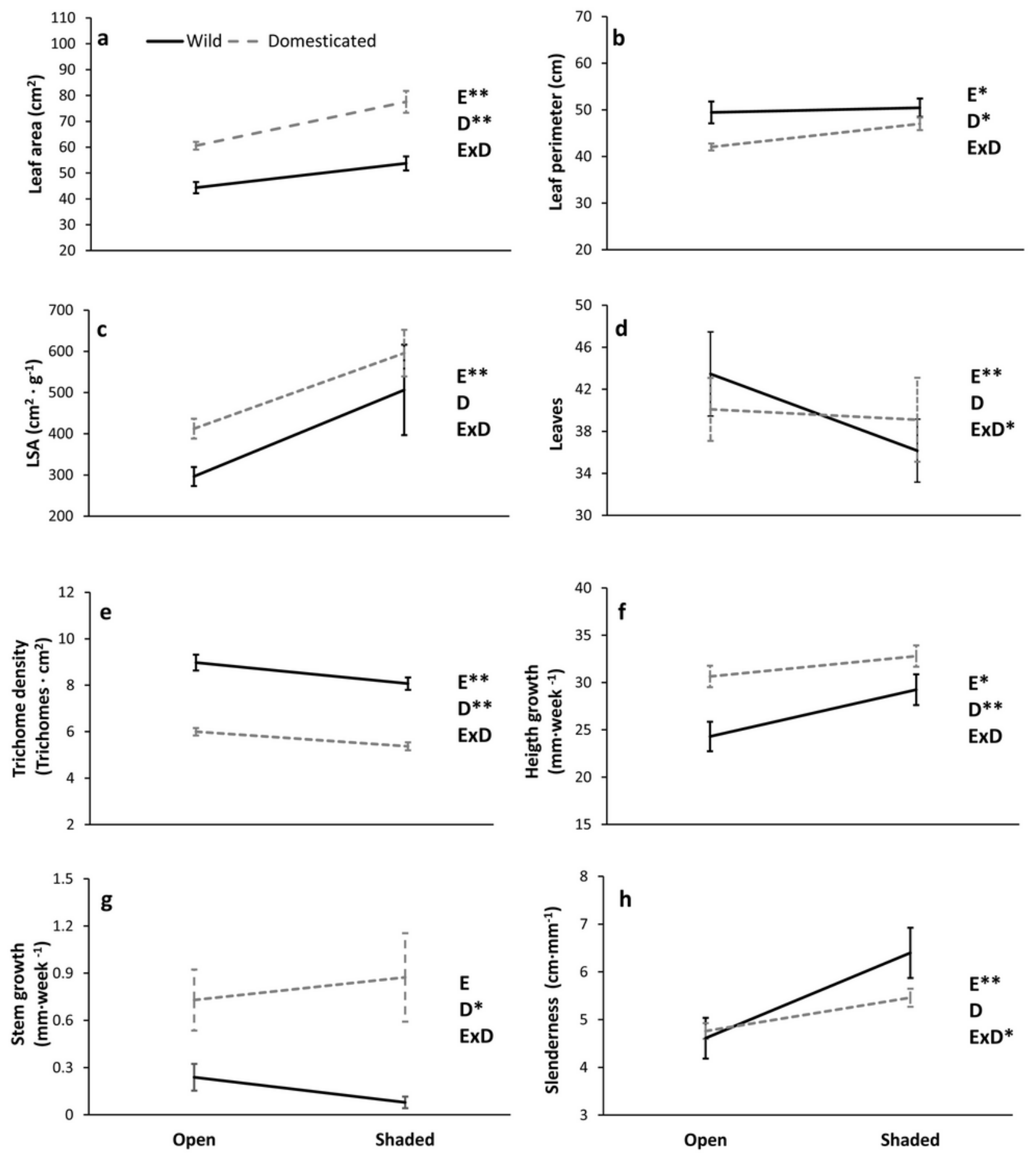

\section{Figure 1}

Reaction norms observed in eight vegetative phenotypic traits in wild and domesticated Cnidoscolus aconitifolius under contrasting light environments: open vs. shaded. Data are mean values \pm 1 standard error. Phenotypic traits measured were: (a) leaf area, (b) leaf perimeter, (c) leaf specific area (LSA), (d) leaf production, (e) trichome density, (f) growth in height, (g) growth in stem diameter and (h) a slenderness index. The letters E (light environment), D (domestication) and E x D (environment x domestication), as 
well as the asterisks $(*=P<0.05, * \star=P<0.01)$ indicates sources of variation tested and their statistical significance.
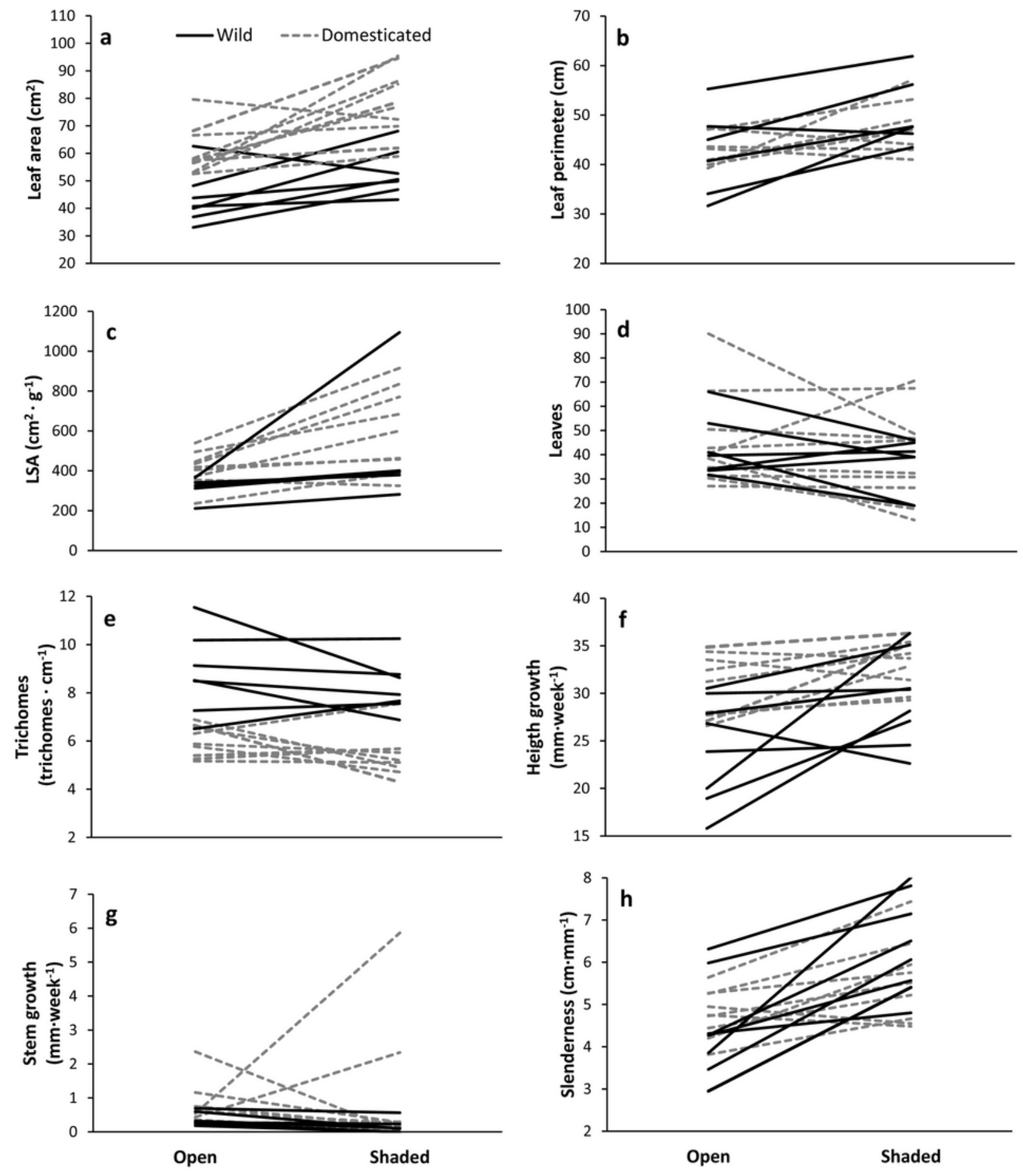

\section{Figure 2}

Reaction norms at genotype level of wild and domesticated Cnidoscolus aconitifolius under contrasting light environments: open vs. shaded. Data are mean values \pm 1 SE. Phenotypic traits measured were: (a) 
leaf area, (b) leaf perimeter, (c) leaf specific area (LSA), (d) leaf production, (e) trichome density, (f) growth in height, $(\mathrm{g})$ growth in stem diameter and $(\mathrm{h})$ a slenderness index.

\section{Supplementary Files}

This is a list of supplementary files associated with this preprint. Click to download.

- SupplementaryMaterialS1.csv 